\title{
Prevalence of Spontaneous Bacterial Peritonitis in Cirrhotic Patients with Ascites and Its Pattern in Aswan University Hospital \\ Mohammed Zain-Eldeen Hafez ${ }^{* 1}$, Hala Abdallah Mahmoud Abdallah' ${ }^{2}$, Khalid Khairy Khalafalla Abdellatif ${ }^{2}$ \\ ${ }^{1}$ Department of Internal Medicine, Faculty of Medicine, Assiut University, \\ ${ }^{2}$ Department of Internal Medicine, Faculty of Medicine, Aswan University \\ *Corresponding author: Khalid Khairy Khalafalla Abdellatif, Mobile: (+20)01000065925
}

\begin{abstract}
Background: Spontaneous bacterial peritonitis (SBP) is the most common infection and a lethal complication in patients with liver cirrhosis and ascites. It has high mortality and recurrence rates and poor long-term prognosis.

Objective: This study was done to determine the prevalence of spontaneous bacterial peritonitis and its variants in patients of liver cirrhosis with ascites.

Patients and Methods: This was a prospective, randomized, cross-sectional clinical study, included 100 adult patients of decompensated liver cirrhosis with ascites in Aswan University Hospital during the period from January 2019 to December 2019.

Results: Diagnosis of SBP is based on ascitic fluid analysis as well as culture and sensitivity. The diagnostic criteria are PMNL $>250 / \mathrm{mm}^{3}$ and or positive culture. Mean of age of patients was $63.06 \pm 9.67$ years old. Majority of patients were males $(63 \%)$ and $37 \%$ were females. In Our study, $62 \%$ of patients were diagnosed SBP. Classic SBP in 30.6\%, Culture Negative Neutrocytic Ascites (CNNA) in 59.7\% and MNB in 9.7\% of patients. Of 25 patients who have positive culture ascetic fluid, $60 \%$ were positive for gram-negative bacteria predominantly E. coli.

Conclusion: Spontaneous Bacteria Peritonitis is the most common and life-threatening infection in patients who have liver

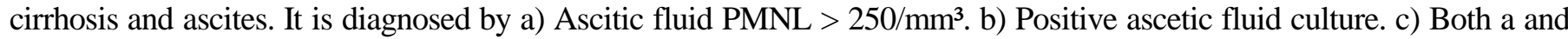
b. It is found that SBP has recently increased in prevalence with predominantly causative organism gram negative E Coli.
\end{abstract}

Keywords: Spontaneous Bacterial Peritonitis, Liver cirrhosis, Ascites.

\section{INTRODUCTION}

Liver cirrhosis is a significant cause of health burden. It is the $14^{\text {th }}$ most common cause of death worldwide ${ }^{(1)}$. In 2010, Egypt had the highest agestandardized cirrhosis mortality rates and almost onefifth $(18.1 \%)$ of all deaths occurred in males (45 to 54 years old) were due to liver cirrhosis (2). Liver cirrhosis also leads to liver dysfunction (impaired synthetic and metabolic functions of the liver) up to liver cell failure. Both portal hypertension and liver cell failure contribute to serious complications e.g. hepatic encephalopathy ${ }^{(3)}$.

The disease can be compensated or decompensated. Significant morbidity and mortality are associated with decompensation. Complications include variceal hemorrhage, ascites, increased risk of bacterial infection, spontaneous bacterial peritonitis (SBP), hepatic encephalopathy, hepatorenal syndrome, hepatopulmonary syndrome, umbilical hernia and hepatic hydrothorax (4). Management should be focused on the prevention of recurrence of complications. Ascites is the most common complication of cirrhosis and is often the first sign of decompensation to appear ${ }^{(5)}$. It occurs within 10 years of diagnosis in half of patients with 5-year mortality of $44 \%{ }^{(6)}$.

Cirrhosis is an immunocompromised state, which predisposes patients to various infections resulting from alterations in defense mechanisms and translocation of gut flora ${ }^{(7)}$. In advanced stages of liver cirrhosis with ascites, patients tend to develop bacterial peritonitis without evidence of source of infection, a form of infection which has been termed spontaneous bacterial peritonitis (SBP) in $1963^{(8)}$.

SBP is the most common and life-threatening infection in patients with advanced liver cirrhosis. Its prevalence is as high as $12 \%$ in hospitalized patients while it develops in up to $3.5 \%$ of patients that are treated as outpatients ${ }^{(\boldsymbol{9})}$. Hospital mortality in patients with SBP reaches 10-20\% with high recurrence rate and so that it has poor long-term prognosis, one-year survival after an episode of SBP is 30-40\% and $20 \%$ at two years ${ }^{(10)}$. SBP is recognized as an important marker of liver disease progression, which might be the decisive watershed in the management of advanced liver disease (11). So it is necessary to consider this diagnosis in every clinical decompensation of a cirrhotic patient, diagnose it early and treat it effectively ${ }^{(\mathbf{1 2})}$.

SBP is defined as the presence of an infection in a previously sterile ascites in the absence of an intra-abdominal source of infection or malignancy ${ }^{(13)}$. The clinical manifestation is nonspecific and variable, up to one third of patients might be asymptomatic (bacterascites) or it can quickly emerge as a fatal sepsis syndrome ${ }^{\left({ }^{10}\right)}$. Presenting signs and symptoms can include fever, changes in mental status, abdominal tenderness, gastrointestinal (GI) bleeding, chills, nausea, or vomiting. Because of the tremendous variability in presentations, and also because such presentations may overlap with other conditions often 
seen in cirrhosis (e.g., encephalopathy), a proper assessment is essential in diagnosis ${ }^{(\mathbf{1 4})}$.

Abdominal paracentesis and ascitic fluid analysis is the gold standard test for diagnosis ${ }^{(14)}$. It is diagnosed by presence of more than 250 polymorphnuclear cells per $\mathrm{mm}^{3}$ of ascitic fluid ${ }^{(13)}$. Bacteriological examination of ascites fluid detects causative agents at less than half of the cases ${ }^{(\mathbf{1 0})}$. It is usually monomicrobial infection and majority of cases are caused by enteric gram-negative organisms, mostly Escherichia coli ${ }^{(\mathbf{1 2})}$. Other causative organisms are Klebsiella pneumoniae, Streptococci spp, Enterobacteriaceae spp ${ }^{(8)}$ and Listeria monocytogenes in a reported case. SBP is an endogenous infection, in general caused by transmigration of enteric bacteria to the ascites ${ }^{(15)}$.

The variants of Spontaneous bacterial peritonitis include: (i) Classic Spontaneous bacterial peritonitis where ascitic fluid polymorphnuclear leukocyte counts more than $250 / \mathrm{mm}^{3}$ and positive culture. (ii) Culture Negative Neutrocytic Ascites (CNNA) but the ascitic fluid polymorphnuclear leukocyte counts more than $250 / \mathrm{mm}^{3}$. (iii) Bacterascites where a culture positive ascitic fluid but the polymorphnuclear leukocyte counts less than $250 / \mathrm{mm}^{3}$ (16).

The result of bacteriological examination is available after a few days. However, empirical treatment should be initiated without delay so that the prognosis becomes better (10). Third-generation cephalosporins or quinolones have been suggested as the empirical treatment for SBP. Early diagnosis and appropriate treatment can help in reducing mortality and morbidity in patients with chronic liver disease (17).

This study was done to determine the prevalence of spontaneous bacterial peritonitis and its variants in patients of liver cirrhosis with ascites.

\section{PATIENTS AND METHODS}

This prospective, randomized, cross-sectional clinical study included 100 adult patients of decompensated liver cirrhosis with ascites in Aswan University Hospital during the period from January 2019 to December 2019.

\section{Inclusion Criteria:}

Adult patients $>18$ years old of both genders who have liver cirrhosis diagnosed on basis of clinical features suggestive of liver disease, biochemical features (modestly elevated liver enzymes, Hypoalbuminaemia, prolonged prothrombin time) and abdominal ultrasound showing features of cirrhosis of liver and portal hypertension.

\section{Exclusion criteria:}

1. Patients who had received antibiotic within 3 weeks prior to admission.
2. Patients classified as having secondary peritonitis diagnosed when one of the following features is present:

a) Selective and persistent localized abdominal pain and tenderness.

b) Presence of following:

i- Ascitic fluid lactic dehydrogenase concentration more than $225 \mathrm{mg} / \mathrm{dL}$.

ii- Ascitic fluid glucose concentration less than $50 \mathrm{mg} / \mathrm{dL}$.

c) Isolation of more than one microorganism in the ascetic fluid culture.

d) An evidence of intra-abdominal surgically treatable source of infection.

3. Tuberculosis of the abdomen with ascites.

4. Malignancy with ascites.

\section{All patients were subjected to the following:}

- Complete Blood Count (CBC).

- Liver function tests: serum level of liver enzymes [alanine transaminase (ALT) and aspartate transaminase (AST)] and serum albumin and bilirubin.

- Coagulation profile: Prothrombin time (PT) and international normalized ratio (INR).

- Kidney function tests.

- Ascitic fluid analysis: All patients underwent paracentesis as soon as the patient is admitted and diagnosed to be suffering from liver cirrhosis, before giving any antibiotic. Ascitic fluid was subjected to cytology, culture and biochemical examination.

\section{Ethical considerations:}

\section{- Research statement:}

1. Ethics Committee, Faculty of Medicine, Aswan University approved the final protocol.

2. Approval of the authority of Aswan University Hospital for final protocol and carrying out the study.

3. Written informed consent was taken from patients who were participating in the study.

4. Before patients are admitted in the study, the purpose and nature of the study as well as the risks were explained to them.

5. Patients must agree that:

a) They understand nature of the study, its inherent risks and benefits.

b) They have the right of refusal to participate in the study and the right of withdrawal from the study at any time without giving any reasons and without 
affecting their right in having proper healthcare in the study site.

c) They have the right to ask any questions regarding the study.

d) They are freely giving informed consent to participate in this study.

- Confidentiality: The confidentiality of all participants admitted to the study was protected to the fullest extent possible. Analysis of data was demonstrated in a secured way without identifying patients' names.

- Informed consent: The signed informed consent form was a permanent part of the participant's study records and was maintained in the same manner as other records.

\section{Statistical analysis}

Recorded data were analyzed using the statistical package for social sciences, version 20.0 (SPSS Inc., Chicago, Illinois, USA). Quantitative data were expressed as mean \pm standard deviation (SD). Qualitative data were expressed as frequency and percentage. The following tests were done:

- Independent-samples t-test of significance was used when comparing between two means.

- Chi-square $\left(\mathrm{x}^{2}\right)$ test of significance was used in order to compare proportions between two qualitative parameters.

- The confidence interval was set to $95 \%$ and the margin of error accepted was set to $5 \%$.

\section{RESULTS}

Table (1): Age and gender distribution for whole group

\begin{tabular}{|l|l|c|c|c|}
\hline \multicolumn{2}{|c|}{} & \multicolumn{1}{|c|}{$\mathbf{N}$} & $\%$ & Median \\
\hline \multirow{3}{*}{$\begin{array}{l}\text { Age } \\
\text { (years) }\end{array}$} & $\begin{array}{l}\text { Mean } \\
\pm \text { SD }\end{array}$ & \multicolumn{2}{|c|}{$63.06 \pm 9.67$} & \multirow{2}{*}{63} \\
\cline { 2 - 4 } & $30-60$ & 40 & $40 \%$ & \\
\cline { 2 - 4 } & $>60$ & 60 & $60 \%$ & \\
\hline \multirow{2}{*}{ Gender } & Male & 63 & $63 \%$ & \\
\cline { 2 - 4 } & Female & 37 & $37 \%$ & \\
\hline
\end{tabular}

The table showed that mean age of patients was $63.06 \pm 9.67$. Majority of patients were males $(63 \%)$ and female patients were $37 \%$.

Table (2): Prevalence of SBP in cirrhotic patients with ascites and variants of SBP

\begin{tabular}{|l|c|c|}
\hline & $\begin{array}{c}\text { Number of } \\
\text { patients }\end{array}$ & Percentage \\
\hline SBP & 62 & $62 \%$ \\
\hline Non SBP & 38 & $38 \%$ \\
\hline Total & $\mathbf{1 0 0}$ & $\mathbf{1 0 0 \%}$ \\
\hline \multicolumn{3}{|c|}{ Variants of SBP: } \\
\hline Classic SBP & 19 & $30.6 \%$ \\
\hline CNNA & 37 & $59.7 \%$ \\
\hline MNB & 6 & $9.7 \%$ \\
\hline Total & $\mathbf{6 2}$ & $\mathbf{1 0 0 \%}$ \\
\hline
\end{tabular}

This table showed that about $62 \%$ of studied patients were diagnosed as SBP with statistically significant result. This indicated high prevalence of SBP in cirrhotic patients with ascites.

Majority of patients were CNNA meaning that they have PMNL > $250 / \mathrm{mm}^{3}$ in ascitic fluid and negative culture with percentage about $59.7 \%$.

Classic SBP patients who had both culture positive ascitic fluid and PMNL > 250/ $\mathrm{mm}^{3}$ were the next being about $30.6 \%$ of total SBP patients. The remaining SBP patients were diagnosed as MNB meaning that they had only culture-positive ascitic fluid with PMNL $<250 / \mathrm{mm}^{3}$. They were about $9.7 \%$ of total SBP patients.

Table (3): Classification of SBP patients according to culture and sensitivity of ascitic fluid and to gram stain

\begin{tabular}{|c|c|c|c|}
\hline & & $\begin{array}{l}\text { Number of } \\
\text { Patients }\end{array}$ & Percentage \\
\hline \multirow{2}{*}{$\begin{array}{l}\text { Culture } \\
\text { and } \\
\text { sensitivity } \\
\text { of ascitic } \\
\text { fluid }\end{array}$} & $\begin{array}{l}\text { Culture } \\
\text { positive }\end{array}$ & 25 & $40.3 \%$ \\
\hline & $\begin{array}{l}\text { Culture } \\
\text { negative } \\
\text { (CNNA) }\end{array}$ & 37 & $59.7 \%$ \\
\hline \multirow{2}{*}{$\begin{array}{l}\text { Gram } \\
\text { stain }\end{array}$} & $\begin{array}{l}\text { Gram } \\
\text { Positive }\end{array}$ & 10 & $40 \%$ \\
\hline & $\begin{array}{l}\text { Gram } \\
\text { Negative }\end{array}$ & 15 & $60 \%$ \\
\hline \multicolumn{2}{|c|}{ Total } & 87 & $100 \%$ \\
\hline
\end{tabular}

This table showed that majority of SBP patients $(59.7 \%)$ had culture-negative ascitic fluid. Majority of culture-positive SBP patients had gramnegative bacteria of about $60 \%$ and gram positive were about $40 \%$.

Table (4): Classification of culture positive SBP according to microorganisms

\begin{tabular}{|c|l|c|c|}
\hline \multicolumn{2}{|c|}{ Micro-organism } & $\begin{array}{c}\text { Number of } \\
\text { Patients }\end{array}$ & Percentage \\
\hline \multirow{2}{*}{$\begin{array}{c}\text { Gram } \\
\text { Negative }\end{array}$} & E. Coli & 10 & $40 \%$ \\
\cline { 2 - 4 } & $\begin{array}{l}\text { Klebsiella } \\
\text { SPP }\end{array}$ & 5 & $20 \%$ \\
\hline \multirow{2}{*}{$\begin{array}{c}\text { Gram } \\
\text { positive }\end{array}$} & $\begin{array}{l}\text { Staph. } \\
\text { Aureus }\end{array}$ & 6 & $24 \%$ \\
\cline { 2 - 4 } & $\begin{array}{l}\text { Streptococcus } \\
\text { SPP }\end{array}$ & 4 & $16 \%$ \\
\hline \multicolumn{2}{|c|}{ Total } & $\mathbf{2 5}$ & $\mathbf{1 0 0 \%}$ \\
\hline
\end{tabular}

This table showed that most of culturepositive SBP patients had E Coli (40\%) followed by Staphylococcus aureus (24\%), Klebsiella SSP (20\%) and Streptococcus SPP (16\%). 
Table (5): Microorganisms in gram negative and gram-positive group

\begin{tabular}{|c|l|c|c|}
\hline \multicolumn{2}{|c|}{} & $\begin{array}{c}\text { Number } \\
\text { of } \\
\text { patients }\end{array}$ & Percentage \\
\hline $\begin{array}{c}\text { Gram } \\
\text { Negative }\end{array}$ & E.coli & 10 & $66.6 \%$ \\
\hline & Klebsiella SPP & 5 & $33.3 \%$ \\
\hline $\begin{array}{c}\text { Gram } \\
\text { positive }\end{array}$ & $\begin{array}{l}\text { Staphylococcus } \\
\text { Aureus }\end{array}$ & 6 & $60 \%$ \\
\cline { 2 - 4 } & $\begin{array}{l}\text { Streptococcus } \\
\text { SPP }\end{array}$ & 4 & $40 \%$ \\
\hline \multicolumn{2}{|c|}{ Total } & $\mathbf{2 5}$ & $\mathbf{1 0 0 \%}$ \\
\hline
\end{tabular}

This table showed that majority of gramnegative culture SBP patients had E.coli (66.6\%) and Klebsiella patients were the least of about $33.3 \%$. Majority of gram-positive culture SBP patients had Staphylococcus aureus (60\%) and Streptococcus SPP patients were the least of about $40 \%$.

\section{DISCUSSION}

In this study that was conducted on 100 patients having decompensated liver cirrhosis, mean age was $63 \pm 9$ years with 63 male patients $(63 \%)$ and 37 female patients $(37 \%)$.

In our study, we found a high prevalence of SBP in 62 patients $(62 \%)$. This agrees with a study by Abeer et al. ${ }^{(18)}$ who found the prevalence of SBP was about $57 \%$ in a study was conducted on 100 cirrhotic, ascetic patients presented to the Internal Medicine Department, Kasr Elaini Hospital, Cairo University, Egypt. Another study by El Gharabawy et al. (19) found that prevalence of spontaneous bacterial peritonitis was about $76 \%$ in 400 patients with liver cirrhosis and ascites admitted to Hepatology Unit at Mansoura Specialized Medical Hospital, Mansoura University, Egypt. In a study by Oladimeji et al. (20) SBP developed in $67.7 \%$ of 31 patients with liver cirrhosis and ascites who were admitted into the Medical Ward of the Ekiti State University Teaching Hospital (EKSUTH), Ado-Ekiti, Nigeria.

According to results of ascitic fluid culture of SBP patients, we found that 37 patients $(59.7 \%)$ among 62 SBP had CNNA with PMNL > 250/ $\mathrm{mm}^{3}$, while $25(40.3 \%)$ patients had culture-positive ascitic fluid. Our study agrees with Purohit et al. ${ }^{(12)}$ who studied 217 clinically suspected cases of SBP. They concluded that $71(43.80 \%)$ had ascitic fluid polymorph nuclear cells (PMN) count $\geq 250 / \mathrm{mm}^{3}, 31$ (43.6\%) cases were culture-positive and $40(56.4 \%)$ cases were culture-negative neutrocytic ascites.

Also, we agrees with El Gharabawy et al. ${ }^{(19)}$ who found that 179 patients (58.3\%) among 400 SBP patients had CNNA while 128 (41.7\%) patients had positive cultures. It was also found that positive cultures were gram-negative in 77 patients $(60.2 \%)$ and gram-positive in 51 patients (39.8\%). But, Oladimeji et al. (20) found that in patients who developed culture-positive SBP was present in $66.7 \%$, while CNNA was found in $33.3 \%$.

In our study, of 25 culture-positive patients, 19 patients (30.6\% of SBP patients) were classic SBP being had PMNL > 250/ $\mathrm{mm}^{3}$ and 6 patients $(9.7 \%$ of SBP patients) were Monobacter Non-Neutrocytic bacterascites (MNB) being had PMNL $<250 / \mathrm{mm}^{3}$. This disagrees with Oladimeji et al. ${ }^{(20)}$ who found that in patients who developed SPB, the prevalence of MNB was $26 \%$.

In our study, we found that positive cultures were gram-negative in 15 patients $(60 \%)$ predominantly E Coli (66.6\%) and Klebsiella (33.3) and gram-positive in 10 patients $(40 \%)$ predominantly Staphylococcus aureus $(60 \%)$ and streptococcus SPP (40\%). This agrees with Oladimeji et al. ${ }^{(20)}$ who found that in those with SBP, 93\% had gram-negative bacilli being responsible in $66.7 \%$ of the cases with $\mathrm{E}$ coli $(70 \%)$ was the predominant organism followed by Klebsiella species. Gram-positive organisms accounted for $33.3 \%$ with Streptococcal species $(60 \%)$ was the predominant organism followed by Staphylococcus aureus (40\%).

For all of 25 culture-positive patients, the causative microorganism was found to be $\mathrm{E}$ coli in 10 patients $(40 \%)$ followed by Staphylococcus aureus in 6 patients $(24 \%)$ and then Klebsiella SPP in 5 patients (20\%) and lastly Streptococcus SPP.

In this study as well as some recent studies, Spontaneous bacterial peritonitis showed increased prevalence in patients who have liver cirrhosis and ascites with predominantly culture-negative variant (CNNA) and causative organisms were predominantly gram-negative bacteria.

\section{CONCLUSION}

Spontaneous bacterial peritonitis is the most common and life threatening infection in patients who have liver cirrhosis and ascites. It is diagnosed by a)

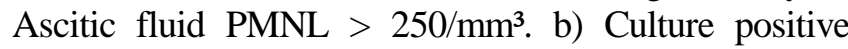
ascetic fluid. c) Both a and b. It is found that SBP has recently increased in prevalence with predominantly causative organism gram-negative E Coli.

\section{RECOMMENDATIONS}

We recommend to consider SBP in deteriorating patients with decompensated liver cirrhosis with ascites and to obtain ascitic fluid samples for analysis and cultures and sensitivity at the time of hospitalization. In addition, it is recommended to early initiate empirical treatment with appropriate antibiotic to get better outcome and reduce mortality and morbidity from spontaneous bacterial peritonitis (SBP) in patients with liver cirrhosis. 


\section{REFERENCES}

1. Tsochatzis E, Bosch J, Burroughs A (2014): Liver cirrhosis. Lancet, 383: 1749-1761.

2. Mokdad A, Lopez A, Shahraz S et al. (2014): Liver cirrhosis mortality in 187 countries between 1980 and 2010: a systematic analysis. BMC medicine, 12: 145-48.

3. Pinter M, Trauner M, Peck-Radosavljevic M et al. (2016): Cancer and liver cirrhosis: implications on prognosis and management. In ESMO Open, 1: 1-16.

4. Bird T, Ramachandran P, Thomson E (2015): Decompensated liver cirrhosis. Anaesthesia \& Intensive Care Medicine, 16: 180-185.

5. Runyon B (2013): Introduction to the revised American Association for the Study of Liver Diseases Practice Guideline management of adult patients with ascites due to cirrhosis 2012. Hepatology, 57: 1651-1653.

6. Ge P, Runyon B (2014): The changing role of betablocker therapy in patients with cirrhosis. J Hepatol., 60: 643-653.

7. Singal A, Salameh H, Kamath $P$ (2014): Prevalence and in-hospital mortality trends of infections among patients with cirrhosis: a nationwide study of hospitalised patients in the United States. Alimentary Pharmacology \& Therapeutics, 40: 105-112.

8. Shi L, Wu D, Wei L et al. (2017): Nosocomial and Community-Acquired Spontaneous Bacterial Peritonitis in patients with liver cirrhosis in China: Comparative Microbiology and Therapeutic Implications. In Sci Rep., 7: 46025-28.

9. Iyyanna G, Manjunath F, Ng T (2017): Prospective study of bedside inoculation of blood culture bottles with ascitic fluid versus delayed inoculation for the detection of spontaneous bacterial peritonitis. DOI: http://dx.doi.org/10.18203/23206012.ijrms20175557

10. Senkerikova R, Frankova S, Sperl J et al. (2015): Spontaneous bacterial peritonitis. Vnitrni Lekarstvi., 61: 134-140.

11. Mandorfer M, Bota S, Schwabl P et al. (2014): Nonselective beta-blockers increase risk for hepatorenal syndrome and death in patients with cirrhosis and spontaneous bacterial peritonitis. Gastroenterology, 146: 1680-1690.
12. Purohit P, Malek S, Desai K et al. (2015): A study of bacteriological profile of ascitic fluid in suspected clinical cases of spontaneous bacterial peritonitis at a tertiary care hospital in India. Inter J Medic Sci Pub Heal., 4 (4): 496-501.

13. Suresh I (2015): Spontaneous ascitic fluid infection in liver cirrhosis: bacteriological profile among patients admitted in a tertiary care hospital, mysore. International Journal of Current Research, 7 (6): 16973-16975.

14. Alaniz C, Regal R (2009): Spontaneous Bacterial Peritonitis: A Review of Treatment Options. https://www.ncbi.nlm.nih.gov/pmc/articles/PMC269 7093/

15. Wiest R, Lawson M, Geuking M (2014): Pathological bacterial translocation in liver cirrhosis. Journal of Hepatology, 60: 197-209.

16. Vidya S, Ravikaladhar R, Chandrasekhar $H$ (2016): A clinical study of spontaneous bacterial peritonitis in cirrhosis of liver with ascites in teritiary care hospital. Journal of Evidence Based Medicine and Healthcare, 3: 36-41.

17. Syed V, Ansari J, Karki $P$ et al. (2007): Spontaneous bacterial peritonitis (SBP) in cirrhotic ascites: a prospective study in a tertiary care hospital. Nepal Kathmandu University Medical Journal (KUMJ), 5: 48-59.

18. Abeer M, Hany M, Nehal H (2008): Prevalence and characteristics of spontaneous bacterial peritonitis in hospitalized patients with ascites due to liver cirrhosis. Cairo University, Giza, Egypt. https://www.google.com/

Characteristics\%2520of\%2520Sponta.pdf\&usg

19. El Gharabawy S, El Mashad N, Sheta $\mathrm{T}$ et al. (2018): Prevalence and microbiological features of spontaneous bacterial peritonitis in hospitalized ascitic patients: Single center study. J Bacteriol Mycol Open Access, 6 (2): 160-163.

20. Oladimeji A, Temi A, Adekunle A et al. (2013): Prevalence of spontaneous bacterial peritonitis in liver cirrhosis with ascites. The Pan African Medical Journal, 15: 128-32. 